\title{
CONFIDENCE BUILDING MEASURES AND EVOLUTION OF RELATIONS BETWEEN PAKISTAN AND INDIA
}

"In South Asian societies, fascism and Jingoism are inflamed in the name of patriotism, nationalism, and religious revivalism, and human hearts and minds are being militarised. But clearly, the impoverished people of the region has nothing to gain from all of this." (Khawaja, 2018, p.3)

\section{Introduction}

South Asia is historically a conflict-prone region with diverse nature of intra-state and inter-state conflicts owing to a wide range of issues including ethnicity, religion, economics, autonomy, border disputes and many more. Pakistan and India's conflict is one of the most protracted conflicts of contemporary times (Michael, 2018, p.1). The primary reasons for the Pakistan and India conflict are the deep-rooted disputes which emerged at the time of independence owing to complex dynamics of partition and diversity of opinion (Paul and Hogg, 2005, p.251). The relations between two nucleararmed states remain in turmoil even after 73 years of independence. There have been numerous efforts on the diplomatic front comprising Confidence Building Measures (CBMs), dialogues, pacts and agreements to resolve the conflict. However, Pakistan and India could not achieve any concrete results except a few brief periods of relatively peaceful coexistence. Therefore, this essay aims to critically analyse the role of Confidence Building Measures in the evolution of relations between Pakistan and India. The essay begins with an overview of the relations/conflicts and a brief history of diplomatic engagements between the two countries since independence from the British rule in 1947. Then the essay attempts to explain the theoretical framework of Confidence Building Measures by analysing the strengths and weaknesses of the CBMs approach. The essay proceeds further to analyse the significant Confidence Building Initiatives between the two countries in various domains of bilateral relations. Subsequently, the essay attempts to identify the spoilers in the relations between the two countries. After identifying the spoilers, the essay suggests the way forward for resolving conflicts and ensuring peace and stability in the region. Finally, the essay concludes by highlighting the role of CBMs to create an environment of mutual trust and cooperation.

\section{Overview of Relations and Diplomatic Engagements}

Multiple wars, major crises, and innumerable exchanges of fire along the LOC over seventy years of independent coexistence constitute an unenviable record for any pair of neighbouring democratic countries. Michael (2018) says that Pakistan and India conflict is one of the longest enduring 
conflicts of contemporary times (p.1). Pakistan and India have common threads of history, culture and language, but both countries are divided by ideology, territorial disputes and conflicts. Pakistan and India, so-called democracies, have had approximately 15 conflicts and crises of varying intensity since their independence from the British rule in August 1947 (Chari et al., 2009, p.15). The prominent conflicts include the First Kashmir War (1947-1949), September 1965 war, 1971 war, and the 1999 Kargil conflict, which is also known as Operation Koh-e-Paima. The significant reasons for this hostility are deep-rooted in the decolonisation process. The issues include territorial disputes, unjustified distribution of resources between two newly created states, migration issues which displaced around 11 million people, and security concerns right from the beginning. Furthermore, Pakistan and India have taken a hard stance for control over economically and the strategically vital valley of Kashmir, which has provoked a perpetual conflict in South Asia. The Kashmir conflict has affected the relationship between both countries in all aspects of social life, and there is no fortune of peace in the foreseeable future (Paul, 2005, p.3).

Makeig (1987) notes that the rivalry between Pakistan and India compels them to employ their limited resources in countering the perceived and actual threats (p.271). The populist narrative in Pakistan is that India is an expansionist and hegemonic state while Indians perceive Pakistan as a revisionist, theocratic and extremist state. These perceptions foster an environment of conflict by polluting the minds of political elites, military and the general public. Moreover, the media in both countries further builds narratives of hatred and violence, which further consolidates the existing perceptions of distrust. Zehra (2018) has summed up the issue by saying the nationalist's narratives have been programmed into the DNAs of people of Pakistan and India to perceive each other as an enemy (p.39). These narratives are being exploited by the political and military elite to fuel conflicts and violence to pursue their personal as well as national political and security objectives. Peaceful relations between the two countries seem ever more elusive over the last couple of years owing to the rise of right-wing Hindu nationalist Bhartiya Janta Party (BJP) in India.

Effendi and Choudhry (2016) analyse that Pakistan and India have taken several bilateral and internationally brokered measures over the last seven decades to resolve the conflicts, but they could not achieve any breakthrough for final settlement (p.187). Most of the diplomatic engagements in the past came up due to a specific set of prevailing or emerging circumstances for crisis and conflict management and were primarily affected by the variables existing at that particular juncture of history. The key variables which have an impact on the diplomatic engagements include domestic political environments, the attitude of political and military leadership, and the role played by 
external actors like the United States, Russia and China. Interestingly, both the countries concluded most historic and significant agreements at the end of the major conflicts and these agreements mainly aimed towards ceasefires, adjustments in the territories gained or lost during the conflict and promises for serious commitments in future (Makeig, 1987, p.272). These agreements did not talk much about the significant issues, including the burning question of Kashmir, which is a central element in Pakistan-India relations. Indus Basin Water Treaty of 1960 is the most critical agreement signed by both countries under auspices of the World Bank without any war and despite concerns from both sides is prevailing till date. The following table gives us an overview of major diplomatic agreements and negotiations between two countries along with the outcomes which are mostly not encouraging (Makeig, 1987); (Effendi and Choudhry, 2016);(Khawaja, 2018). Keeping in mind this turmoiled history of relations and failed attempts for peace, it is pertinent to view the role of CBMs for the evolution of peaceful relations in future. The next section of the essay will focus on the theoretical perspectives of CBMs.

\begin{tabular}{|c|c|c|c|}
\hline $\begin{array}{c}\text { Title of } \\
\text { Agreement }\end{array}$ & Objective & $\begin{array}{c}\text { Facilitated } \\
\text { By }\end{array}$ & Outcome \\
\hline Ceasefire, 1949 & Ceasefire in Kashmir & United Nations & Partial Success \\
\hline $\begin{array}{l}\text { Liaqat-Nehru } \\
\text { Agreement } 1950\end{array}$ & $\begin{array}{l}\text { For minority rights of } \\
\text { migrating Muslims and } \\
\text { Hindus }\end{array}$ & Bilateral & Partial Success \\
\hline $\begin{array}{l}\text { Indus River Waters } \\
\text { Treaty (1960) }\end{array}$ & Sharing of Rivers & World Bank & $\begin{array}{l}\text { Successful with few } \\
\text { concerns about Violations }\end{array}$ \\
\hline $\begin{array}{l}\text { Tashkent Declaration } \\
\text { (1966) }\end{array}$ & To conclude the 1965 war & Russia & Failure \\
\hline Simla Accord (1972) & $\begin{array}{l}\text { Agreement for future } \\
\text { relations and settlements } \\
\text { after the } 1971 \text { war }\end{array}$ & Bilateral & $\begin{array}{c}\text { Failure mainly because of } \\
\text { many conflicts after the } \\
\text { agreement }\end{array}$ \\
\hline $\begin{array}{l}\text { Lahore Declaration } \\
1999\end{array}$ & $\begin{array}{l}\text { Settlement of Issues and } \\
\text { positive engagement for } \\
\text { dialogue }\end{array}$ & Bilateral & $\begin{array}{l}\text { Failure due to Kargil } \\
\text { conflict }\end{array}$ \\
\hline Agra Summit 2001 & Breaking Ice after Kargil & Bilateral & Inconclusive \\
\hline $\begin{array}{l}\text { Islamabad Summit } \\
2004\end{array}$ & $\begin{array}{l}\text { The way forward for } \\
\text { Peaceful Relations }\end{array}$ & Bilateral & $\begin{array}{l}\text { Major Breakthrough but no } \\
\text { concrete results }\end{array}$ \\
\hline
\end{tabular}




\begin{tabular}{|c|c|c|c|}
\hline $\begin{array}{c}\text { Composite Dialogue } \\
\text { 2004-08 }\end{array}$ & $\begin{array}{l}\text { Engagements at Multiple } \\
\text { levels to resolve the issues }\end{array}$ & Bilateral & $\begin{array}{c}\text { A breakthrough on Kashmir } \\
\text { was expected in } 2008 \text {, but } \\
\text { Samjhota Express bombings } \\
\text { and Mumbai Attacks spoiled } \\
\text { the relations }\end{array}$ \\
\hline $\begin{array}{l}\text { Shanghai Cooperation } \\
\text { Organisation Meeting } \\
2015\end{array}$ & $\begin{array}{c}\text { Engagement in multiple } \\
\text { domains for better } \\
\text { relations }\end{array}$ & $\begin{array}{c}\text { Bilateral } \\
\text { declaration on a } \\
\text { multilateral } \\
\text { Forum }\end{array}$ & $\begin{array}{l}\text { The CBMs not materialised } \\
\text { due visit of Kashmiris and } \\
\text { following backlash }\end{array}$ \\
\hline $\begin{array}{l}\text { Kartarpur Corridor } \\
2019\end{array}$ & $\begin{array}{l}\text { Pakistan's initiative to } \\
\text { accommodate Sikh } \\
\text { Pilgrimage at Nankana } \\
\text { Sahib }\end{array}$ & Bilateral & $\begin{array}{l}\text { Successful despite } \\
\text { prevailing border tensions. } \\
\text { The international } \\
\text { community highly } \\
\text { appreciated the agreement. }\end{array}$ \\
\hline
\end{tabular}

Table 1: Major Diplomatic Engagements between Pakistan and India

\section{Confidence-Building Measures Theoretical Perspective}

CBMs are regarded as alternatives to the traditional diplomatic business which can halt due to numerous factors comprising but not limited to a trust deficit, security concerns and stalemates in negotiations. The acronym Confidence-Building Measures was first used in the Conference on Security and Cooperation in Europe (CSCE) which held in Helsinki in 1975. The origins of CBMs can be traced back in Helsinki final act, Vienna document and Stockholm document on Confidence and Security Building Measures (OSCE Secretariat's Conflict Prevention Centre, 2012, p.5). CBMs gained momentum during and after the Cold War period and mainly aimed to build confidence among the two major powers, USA and USSR, on issues like arms control, war prevention, conflict resolution and nuclear proliferation. Khawaja (2018) argues that the post-Cold war strategies of CBMs aimed at multidimensional approaches for conflict resolution at state as well as the domestic level (p.4). Alford (1979) argues that demilitarisation mechanisms for the Rhineland in the aftermath of first world war and the establishment of a hotline between former USSR and USA in 1963 fall under the umbrella of CBMs (p.1). Therefore, we can say that CBMs are not new to the world but owing to rapid advancements in technology and expanding layers of interaction between states, the scope of CBMs has significantly enlarged in contemporary times.

In stark contrast to the other instrument of foreign policy where theories precede practice, practice preceded theory in case of CBMs (Desjardins, 2014, p.7). Therefore, there is no universal definition 
and theoretical framework for CBMs, so the essay will focus upon various definitions of CBMs to design a theoretical framework. The Helsinki conference of 1975 aimed for three significant goals through CBMs: restrain actions causing tension, reduce the possibility of wars due to misconceptions and foster an environment of confidence and cooperation (Desjardins, 2014, p.7). Moreover, the United Nations Office of Disarmament Affairs (2002) defines CBMs as "planned procedures to prevent hostilities, to avert escalation, to reduce military tension, and to build mutual trust between countries. They have been applied since the dawn of civilisation, on all continents." The United Nations definition mainly focuses on security issues and conflict resolution, while neglects the nonmilitary aspects of CBMs. Desjardins (2014) definition of CBMs comprises the actions like two-way communication enhancement, exchange visits and inspections, setting rules for military exercises, social and cultural measures and cooperation in various domains (pp. 5-6). The analysis of the above definitions reveals that the Cold War CBMs mostly focussed on the security-related issues to avoid any circumstances which can lead to a catastrophe and paid little attention towards cooperation in other fields. Landau and Landau (1997) say that "CBMs can be grouped into four general categories: those that demonstrate a willingness to talk, those that demonstrate a willingness to listen, those that demonstrate a willingness to meet the needs of the other party, and those that demonstrate a willingness to improve the long-term relationship with the other party" (p.100). Landau and Alfrod base their arguments on similar grounds of bringing conflicting partied to the negotiations through means other than direct negotiations which may give some results in a short time but might not sustain for longer.

OSCE Secretariat's Conflict Prevention Centre (2012) categorises CBMs into military and nonmilitary domains and identifies five sublevels of non-military CBMs comprising: military, political, economic, cultural and Societal (pp.9-10). CBMs can be employed in multiple domains like measures to diffuse or restrain tensions, conflict resolution, encourage willingness for cooperation, transforming attitudes and finally achieving sustainable peace between the conflicting parties. Vohra and Ansari (2003) argue that CBMs are defined more comprehensively in South Asian perspective as these should include not only military domain instead CBMs should also equally focus on soft nonmilitary issues like economics, environment, education, water, shipping, power and technology (pp.7-8). These arguments take into account both military and non-military CBMs being an integral part of the peace process. CBMs are long term efforts and may not yield immediate results like traditional diplomacy, but they are aimed to achieve ultimate objectives in longer run. 
Furthermore, CBMs are not a zero-sum game and considered easy to negotiate and generally apply to all states involved. CBMs adopt a bottom-up approach and start with smaller issues in contrast to the top-down approach in traditional diplomacy. However, the critiques of CBMs doubt the effectiveness of CBMs vis-a-vis the advertisement of CBMs. They base this argument on the fact that West European states which suggested CBMs at CSCE did not trust the East European states in Warsaw pact (Desjardins, 2014, p.4). The success of CBMs in arms control and security issues remained marginal owing to the mutual trust deficit among different players. Moreover, CBMs capacity to achieve the desired results in military domains depends upon the willingness of adversaries who lack confidence in each other but are willing to avoid conflict (Alford, 1979, p.13). Based on the discussion, the essay adopts the definition of CBMs given by Vohra and Ansari (2003) and focuses on the following domains to evaluate relations between Pakistan and India:

(a) CBMs in Military and Nuclear domain

(b) CBMs in Political and Conflict Resolution Domains

(c) $\mathrm{CBMs}$ in Economic Domain

(d) CBMs in Societal and Cultural Domains

\section{Critical Analysis of CBMs between Pakistan and India}

There have been numerous efforts for restoring confidence among both the adversaries through various mechanisms, but no concrete results achieved over the past 73 years except a few brief periods of negative peace. India and Pakistan have also addressed each other with proposals for joint defence, CBMs, no-war pacts, friendship treaties, and other arrangements aimed at achieving peace. However, most of these initiatives have been diplomatic gamesmanship some of it sincere perhaps, but peace in South Asia remains as uncertain as war. The processes of CBMs between Pakistan and India are complex owing to a fractured history rooted in issues like land disputes, water resources, suspicion, security, arms race, and threat perception (Jabeen et al., 2010). Both the countries devise CBMs in good faith to address various issues, but implementation remains the major challenge owing to the diverging interests and trust deficit. The essay will now focus on the specific areas outlined in the theoretical framework.

\section{(a) CBMs in Military and Nuclear domain}

CBMs in Military aspects also known as Military Confidence-Building Measures (MCBM) comprise a variety of actions including the exchange of vital information; notifications regarding exercises and tests, observation measure, arms control and reduction measures. Multidimensional issues between 
the two countries hindered the success and progress of CBMs in the military and nuclear domains. The unresolved territorial disputes and associated security concerns play a significant role in shaping and projecting the force postures of Pakistan and India towards each other. The action-reaction cycle compounds the situation as the increase in capabilities of one country undermines the security of the other, the classic realist thinking. Pakistan and India's strategic anxieties towards each other also play a substantial role in shaping the relations and implementation of military CBMs. The Indo-Pak region is termed the $2^{\text {nd }}$ nuclear flashpoint of Asia after the Korean Peninsula, where chances of escalation from conventional to nuclear war remain high (Khawaja, 2018, p.109). Chari (2005) also supports the argument that South Asia is the most dangerous place on planet earth, and Kashmir is the nuclear flashpoint in South Asia (p.211).

Pakistan and India have engaged in military and nuclear CBMs on numerous occasions despite noncordial relations. The first step in the military CBMs was the establishment of a hotline between the militaries in 1971 following the model of the United States and USSR military communication in the same timeframe (Ahmar, 2001, p.87). However, the hotline between Director Generals Military Operations of both countries remained symbolic, and no practical advantages could be achieved for maintaining peaceful relations. The hotline works well during peacetime while gets suspended during the crises build-up, rendering it useless in true essence. The sitting Prime Ministers of Both countries, Benazir Bhutto and Rajiv Gandhi, inked the next major CBM under the umbrella of Nuclear Threat Initiatives. This CBM aimed to prevent attacks on nuclear facilities of each other and do not provide any assistance to foreign ally for attacking such installations (Khawaja, 2018, p.119). This measure enabled the exchange of list of nuclear facilities between both the countries in 1992 (Shahid-ur-Rehman Khan, 1992). This CBM initiative helped to build trust and both the nuclear rivals respected the arrangements during the peace as well as crises. Later in 1991, Pakistan and India CBMs progressed further, and they signed an agreement for prior notification regarding military exercises and air space violations, especially near LoC. This set of CBMs opened further channels of communication in military and diplomatic domains to avoid repetition of crises but could not achieve the desired results owing to non-availability of implementation structures.

The next milestone in CBMs was the 1992 agreement on the complete prohibition of chemical weapons, and both countries declared that they do not possess chemical weapons. However, these CBMs suffered a considerable setback once India declared its chemical weapons arsenal under the Chemical Weapons Convention (Nuclear Threat Initiative, 2011a). Such incidents created further suspicion among both the countries already having problematic relations and halted the advancement 
in the process of confidence-building. Pakistan considered this incident as a violation of the bilateral agreement which widened the gulf of trust deficit between the two countries. In the backdrop of this incident, no further progress achieved until 1999. Later, Nawaz Sharif and Vajpayee concluded the Lahore Accord in 1999, which was a milestone agreement for peace-building following the nuclear tests in 1998. This agreement incorporated the concept of developing and employing CBMs in both conventional military and nuclear domains to avoid any untoward nuclear weapons launch situation and to reduce prospects for future conflicts (Nuclear Threat Initiative, 2011b). This set of CBMs was undermined by the Kargil conflict, which started a few months after the declaration. This time it was the Pakistani side which undermined the peace efforts because political and military leadership were not on the same page. Here one can analyse that the political leadership tried to put in mechanisms for peaceful coexistence, but the military institution spoiled the efforts. This problem necessitates the requirement of structures which can implement and sustain the CBMs without significant interference from any state institution, military in particular.

From 1999 to 2003, the tensions remained high between both the states due to large scale deployments along the LoC, terrorist attacks in Srinagar and on the Indian parliament. UN Generally Assembly session of 2003 carved way for a ceasefire and later on direct negotiations between the political leadership of both countries (Khawaja, 2018, pp.120-121). A new set of military and nuclear CBMs was worked upon which included reduction of troops along LoC, no further development of military posts and prior information regarding the testing of ballistic missiles (Krepon, 2017). However, all these CBMs halted in 2008 after the terrorist attacks in Mumbai for which India blamed Pakistan. Later on, few efforts were initiated in 2014 and 2015, but those did not work owing to preexisting notions of trust deficit and accusations for terrorist attacks. The primary issues in the implementation of the military and nuclear CBMs are non-availability of a framework, transparency issues and lack of trust. The political will also play a significant role in the success of military and Nuclear CBMs, but military and security concerns undermine political will. Furthermore, Pakistan and India are so-called democratic countries, but they do not have liberal democratic structures and separation of power remains a contentious issue. Additionally, the policies adopted through CBMs were not compatible with the follow on actions because military and political leadership in both countries were suspicious about each other. These issues obstructed the implementation of military and nuclear CBMs in letter and spirit. The recurring crises between Pakistan and India after the Pulwama attacks of 2019 highlight the shortfalls of the concept of nuclear deterrence between both the South Asian neighbours. 


\section{(b) CBMs in Political and Conflict Resolution Domains}

The political leadership of both countries have engaged in multiple layers of CBMs to create an environment for resolving the conflicts, but the CBM processes got undermined by the non-flexible red lines set by the respective governments and state institutions (Khawaja, 2018, pp.25-26). The very first CBM was the signing of an agreement for the protection of the people migrating from both sides as many atrocities happened, especially with women and children. Nevertheless, this process stalled very soon owing to transparency issues and lack of supporting mechanisms. Most of the diplomatic initiatives mentioned in Table: 1 above failed to achieve desired results due to similar issues. The political will is the most significant factor in the implementation of any type of CBMs. Khan (2010) argues that the significant treaties between Pakistan and India emerged after crisis and wars (P.109). This argument implies that crisis management was the primary objective of the CBMs, while both sides did not exert incremental efforts to achieve sustainable peace. The Indus Basin water treaty was inked because of the conflict on the division of water, and many political and conflict resolution CBMs like Shimla agreement came in the aftermath of the war of 1971.

There are numerous CBMs in the political domain, but only a few gave some dividends of peace to both countries. Musharraf, Vajpayee and Manmohan regimes can be regarded as more encouraging for implementation of political CBMs, but the Mumbai attacks of 2008 undermined the viability of all CBMs in this domain. Kashmir issue was about to be resolved when the Mumbai attacks stalled the process. The latest set of CBMs was agreed between then Prime Ministers of both countries during the Shanghai Cooperation Organisation summit in Ufa, Russia in 2015 (French, 2019, p.121). A diverse range of measures were agreed upon in military, political, economic and societal domains. However, the visit of Kasmiri leaders at Pakistan High Commission in India undermined the implementation of this important deal. The political elite and the media in both countries played a vital role in debilitating the way forward. Both countries engaged in a vicious cycle of the blame game, causing further deterioration in relations.

\section{(c) CBMs in Economic Domain}

The growth of economic cooperation in South Asia is not encouraging, owing to several inter-state and intra-state conflicts. SAARC also failed to achieve its mandate of regional cooperation in various domains because both the key players Pakistan and India created problems in the effective functioning of the organisation. India is among one of the major growing economies of the world while Pakistan is still struggling with the economy and recovering from the aftershocks of the global 
war on terror. Naz (2012) argues that the conflicting political aspirations of both countries are significant barriers to economic integration (p.12). Both countries have a vast potential for bilateral trade and engagement in other activities vital for economic growth, but the enduring rivalry undermines this significant aspect of bilateral relations. The economic cooperation is a hostage to the political turmoil and misconceptions rather than being a free market economy to create a win-win situation for both the countries (Khawaja, 2018, p.150). The Kashmir issue and underlying politics also have a detrimental effect on the economic cooperation between the two countries.

Gopinath (2012) examines the complicated economic relationship between Pakistan and India as a multidimensional stockpile of layers of mutual mistrust and sentiments emerging from shared cultures (p.23). There have been numerous trade agreements and economic CBMs between both the countries but with no viable improvement in the economic landscape. During early years after independence, both the countries agreed on several economic agreements mainly aimed to avoid double taxation, facilitation of trade, food and goods trade, banking sector and air services (Mahmood, 2013, p.20). However, the growth of trade over the past few years is not encouraging, and closing of borders on trivial matters has become a norm in bilateral relations between the two countries. The imposition of reciprocating tariffs is also a regular practice to discourage products from each other, and this vicious cycle challenges the CBMs in the economic domain.

There are three distinct phases for analysing the economic interactions and CBMs between Pakistan and India (Khawaja, 2018, p.159). The first phase lasted from 1947 to 1956, where Pakistan and India were the most significant trading partners because of existing arrangements and low intensity of the conflict. There was some level of mutual trust, and perceptions towards each other were generally positive. The decade after the 1965 war is recognised as worst in terms of economic cooperation where it decreased to minimal. There was an agreement in 1974, and certain CBMs were adopted, but no significant improvement happened due to misconceptions and two wars in a short period of six years. A Joint Commission for the promotion of economic cooperation was established in 1983, but the ensuing crisis like the Siachin issue and the Brasstacks undermined this initiative.

The third phase started in the 1990s with a relative improvement in bilateral trade, and India granted Most Favoured Nation (MFN) status to Pakistan in 1996. However, real benefits could not be reaped as Pakistan did not reciprocate the MFN status for India. Moreover, the composite dialogue process (2004-2008) provided an excellent platform for negotiations on the improvement of the bilateral economic relationship. Two thousand eleven (2011) marks the breakthrough year for the 
improvement of the economic relations due to CBMs, where both countries agreed on the implementation of the South Asia Free Trade Agreement (SAFTA). This phase of CBMs helped both countries to build strong economic relations and many new ventures like Wagah-Attrai crossing opened for cross border trade. The people associated with trade and commerce in both countries played a decisive role in the implementation of CBMs supported by the respective political leadership. The Iran-Pakistan-India (IPI) gas pipeline was a significant project agreed through CBMs but still in turmoil owing to India-Pakistan mutual distrust. The recent developments in the region after the Pulwama attacks in 2019 have seriously harmed the economic ties between the two countries. Both countries have not exerted any further efforts to reduce tensions, and most of the existing CBMs stand suspended since last one year. Nevertheless, economic interdependence between the two countries can play a significant role in conflict resolution, as suggested in the theory of complex interdependence.

\section{(d) CBMs in Societal and Cultural Domain}

Civil society plays a vital role in influencing and shaping how individuals, communities, institutions, and states behave with each other. The CBMs which promote people to people contacts play a significant role in developing an environment for cordial relations and conflict resolution. Societal and cultural CBMs based on humans can be very useful in countries like Pakistan and India, where the state narratives are generally built to perceive others as the enemy (Khawaja, 2018, p.169). Cultural and societal CBMs aim for new ventures and common grounds to develop a sense of belongingness while keeping in mind the respective cultures and authorities. Pakistan and India concluded the Cultural Cooperation Agreement in the early 1990s along with a set of military CBMs. Both the governments established a joint commission under this agreement to formulate strategies for improving relations and cooperation in fields comprising education, art, culture, sports, and mass media (Khan, 2010, pp.137-138). However, the commission was able to arrange only a few activities to increase people to people contacts through student exchange programs, cultural events, and sports events. The scale of activities remained insignificant to achieve the broader objective of improvement in relations. The first decade of the $21^{\text {st }}$ century witnessed an increase in peoples to peoples contact and non-formal diplomacy between the two countries alongside formal engagements in the composite dialogue process. Recently, the opening of the Kartarpur corridor in 2019 for the Sikh pilgrimage, amidst massive tensions, has been widely applauded by the international community. 


\section{Major Spoilers in Pakistan-India Relations}

CBMs between Pakistan and India are designed with the inherent mind-set of conflicting ideologies, antagonising perceptions and security dilemmas. The CBMs playing field is complicated owing to parochial dimensions caused by a multitude of factors like mutual distrust, suspicion, troubled sociopolitical history, and paranoia against each other. The majority of the general public in Pakistan and India criticise their respective governments and leadership for spoiling relationships while people want to live in peace (Khawaja, 2018, p.166). Based on the analyses, the essay identifies the following main spoilers in Pakistan-India relations:

(a) One of the major spoilers in the political domain is the exploitation of voters' bank, especially in India, where domestic politics undermined the relations between both the countries. The politicians adopt the narrative to take a stricter stance against the other country as was done by Modi before elections in 2019, which resulted in the exchange of airstrikes and shooting down of fighter aircraft. Both the countries reached the brink of nuclear war owing to the political spoilers being played by BJP to win elections. Military and nuclear CBMs were adopted to avoid conflicts and miscalculations for nuclear weapons, but a terrorist attack can bring both nations to the brink of a nuclear/conventional war.

(b) The non-state actors play a fundamental role in undermining the relations and peace efforts between both countries. The terrorist attacks and other such incidents happening in India are perceived being orchestrated by Pakistan and vice versa owing to trust deficit. The non-state actors exploit the lack of trust and non-availability of transparent communication channels between both the countries.

(c) The incumbent governments in both countries devise the short term state policies of violence, especially once the parties with an extreme nationalist ideology like BJP come into power. Such parties adopt a rigid stance on bilateral issues to undermine the bilateral relations to a greater extent.

(d) The violation of already agreed upon agreements and CBMs is also a significant impediment and spoiler for existing and future CBMs. The agreement on nuclear and biological weapons, Ceasefire violations along the Line of Control, and Indus Basin water treaty violation are the classic manifestation of this issue.

\section{Way Forward for Sustainable Peace through CBMs}

Khawaja (2018) argues that the region cannot have sustainable peace due to a lack of confidence, which undermines the efforts for peaceful coexistence (p.2). The prospects for a permanent peace 
between India and Pakistan are of the utmost concern for security, stability, and prosperity in the region. Currently, a deadlock persists between the two countries owing to a series of issues in the past few years. Effendi and Choudhry (2016) suggest that "a purposeful set of CBMs entails efforts and initiatives that help parties to open up and continue communication, bringing a good level of trust in the relationship and promising sustainability of the measures in future" (p.188). Pakistan and India can adopt the following measures to foster peaceful relation:

(a) The presence of WMDs on the inventories of both the countries necessitates the CBMs framework, which can reduce the chances of use of such weapons. The existing CBMs in this domain may be revised as per the prevailing environment to ward off the threat of nuclear escalation. Both countries need significant efforts to build trust in this particular domain for regional as well as international peace and security.

(b) The dynamics of military CBMs mainly depend upon four pre-conditions that include continuous negotiations and talks, consistent implementation, transparency of sharing information, and cooperation in other domains including economic, political and social policies (Khawaja, 2018, p.123). Pakistan and India need to devise military CBMs in line with this framework to gain maximum benefits.

(c) Multiple credible channels of communication may be established at various levels and between numerous organisations like Air Forces, Navy, Coast Guard and National Security Advisers to build and maintain credibility. These communication channels will enhance the exchange of information to remove suspicion and reduce the effectiveness of spoilers in the information domain.

(d) Both countries may introduce CBMs in visa regimes to support tourism, businesses, art, culture, and sports. These measures will, in turn, enhance societal interaction to deconstruct the established notion of animosity towards each other, which is a pre-condition for peaceful relations.

(e) CBMs relating to environmental protection and climate change domains are also essential and can play a significant role to mitigate the crisis.

\section{Conclusion}

Pakistan and India inked several agreements and agreed on numerous CBMs, but neither of this restored confidence and misperceptions prevailed. The relations between Pakistan and India are sabotaged by several factors which yield to failure of CBMs, less flexibility towards rapprochement, and numerous episodes of trust-shattering incidents. Most of the CBMs initiatives failed in the past owing to lack of transparency, weak political will and non-availability of implementation structures. 
The CBMs were largely negotiated after major conflicts while both sides made no further efforts to adopt innovative approaches for building confidence. Moreover, people on both sides of the borders share many commonalities and have a strong desire to live in peace. Therefore, Pakistan and India require a comprehensive and integrated approach for CBMs in political, military, economic, environmental and social domains to foster an environment of mutual trust and peaceful coexistence. Both countries must make sincere efforts to restore confidence and closely cooperate on the issues which create a trust deficit. Well structured, pragmatic and institutionally implementable CBMs can bring peace to the region which has seen seven decades of antagonism between the two countries.

\section{Bibliography}

Ahmar, M. 2001. The Challenge of Confidence-Building Measures in South Asia: Har-Anand Publications.

Alford, J. 1979. Confidence-Building Measures in Europe: The Military Aspects. Adelphi Papers, 19(149), 4-13.

Chari, P. R. 2005. Strategic Stability in South Asia: The Role of Confidence-Building and Threat Reduction Measures. Contemporary South Asia, 14(2), 211-217 https://doi.org/10.1080/09584930500314318.

Chari, P. R., Cheema, P. I. \& Cohen, S. P. 2009. Four Crises and a Peace Process: American Engagement in South Asia, Washington D.C.: Brookings Institution Press.

Desjardins, M.-F. 2014. Rethinking Confidence-Building Measures: Routledge.

Effendi, M. S. \& Choudhry, I. A. 2016. India-Pakistan Cbms since 1947 a Critical Analysis. South Asian Studies, 31(1), 187.

French, R. W. 2019. Constructing Cooperation: A New Approach to Confidence Building between India and Pakistan. The Round Table, 108(2), 121-144.

Gopinath, M. 2012. Processing Peace: To Speak in a Different Voice. Peace Prints: South Asian Journal of Peacebuilding, 4(2).

Jabeen, M., Mazhar, M. S. \& Goraya, N. S. 2010. Saarc and Indo-Pak Relationship. Journal of Political Studies, 17(2), 127.

Khan, F. H. 2010. Prospects for Indian and Pakistani Arms Control and Confidence-Building Measures. Naval War College Review, 63(3), 105.

Khawaja, A. S. 2018. Shaking Hands with Clenched Fists: The Grand Trunk Road to Confidence Building Measures between Pakistan and India: National Defence University.

Krepon, M. 2017. South Asia Confidence Building Measures (Cbm) Timeline. Stimson Center, April, 14. 
Landau, D. \& Landau, S. 1997. Confidence-Building Measures in Mediation. Mediation Quarterly, 15(2), 97-103.

Mahmood, Z. 2013. Moving toward Pakistan-India Trade Normalization: An Overview. PakistanIndia Trade.

Makeig, D. C. 1987. War, No-War, and the India-Pakistan Negotiating Process. Pacific affairs, 271294.

Michael, A. 2018. Realist-Constructivism and the India-Pakistan Conflict: A New Theoretical Approach for an Old Rivalry. Asian Politics \& Policy [Online], 10. Available: https://onlinelibrary.wiley.com/doi/abs/10.1111/aspp.12365.

Naz, A. 2012. Political Dominance or Economic Gains: A Case Study of India-Pakistan Trade and Perceptions of the People of Pakistan. South Asian Journal of Peace building, 4(2).

Nuclear Threat Initiative. 2011a. India-Pakistan Agreement on Chemical Weapons [Online]. Available: https://www.nti.org/learn/treaties-and-regimes/india-pakistan-agreement-on-chemicalweapons/\#: :text=India\%20signed $\% 20$ the $\% 20 \mathrm{CWC} \% 20 \mathrm{on}$, not $\% 20$ possess $\% 20$ chemical $\% 20$ weapo ns'\%20stockpiles. [Accessed 0903 2020].

Nuclear Threat Initiative. 2011b. Lahore Declaration [Online]. Available: https://www.nti.org/learn/treaties-and-regimes/lahore-declaration/ [Accessed 0903 2020].

Osce Secretariat's Conflict Prevention Centre 2012. Osce Guide on Non-Military ConfidenceBuilding Measures (Cbms) Vienna: Organisation of Security and Cooperation in Europe.

Paul, T. \& Hogg, W. 2005. South Asia's Embedded Conflict: Understanding the India-Pakistan Rivalry. The India-Pakistan Conflict: An Enduring Rivalry, 251-66.

Paul, T. V. 2005. The India-Pakistan Conflict: An Enduring Rivalry. Cambridge University Press.

Shahid-Ur-Rehman Khan, I. 1992. Pakistan Exchange Lists of Nuclear Facilities'. Nucleonics Week, 10 .

United Nations Office of Disarmament Affairs. 2002. Military Confidence-Building [Online]. United Nations. Available: https://www.un.org/disarmament/cbms/ [Accessed 2702 2020].

Vohra, R. B. R. A. \& Ansari, H. M. R. A. 2003. Confidence Building Measures at Sea: Opportunities for India and Pakistan. Sandia National Laboratories.

Zehra, N. 2018. From Kargil to the Coup: Events That Shook Pakistan: Sang-e-Meel Publications. 